\title{
Articulações em rede e acontecimentos no território: subsídios teóricos para a formação de políticas públicas para o desenvolvimento
}

\author{
Joints in networks and events in territory: theoretical basis for development-oriented \\ public policies.
}

\author{
Sueli Goulart ${ }^{1}$ \\ Marcelo Milano Falcao Vieira ${ }^{2}$ \\ Camila Furlan da Costa ${ }^{3}$ \\ Glauco da Costa Knopp ${ }^{4}$
}

\begin{abstract}
Resumo
Neste artigo, abordamos construtos, conceitos e categorias da geografia, à busca de elementos para a formação de políticas públicas direcionadas ao desenvolvimento. As razões que nos impelem a essa aproximação se relacionam ao contexto geopolítico contemporâneo e à banalização de conceitos como território, por exemplo, usado como mero designativo de um espaço qualquer, sobre o qual se aplicam metodologias, muitas vezes, vinculadas a políticas públicas inspiradas em modelos exógenos. Concluímos que a aproximação à concepção de território indica a necessidade de assumir o caráter relacional das articulações que ocorrem em espaços sociopolíticos construídos por atores sociais e governamentais. Essa necessidade é tanto mais relevante quanto mais se observam iniciativas que vêm sendo encaminhadas no plano federal, no sentido de recuperar a capacidade de planejamento e promoção do desenvolvimento, mediante a formação e a articulação de políticas públicas de âmbito nacional, regional e local.
\end{abstract}

Palavras-chave: redes sociais; redes organizacionais; território; políticas públicas; desenvolvimento.

\begin{abstract}
In this essay we use constructs, concepts and categories from geography in order to search for elements that could help in the formation of public policies oriented for development. The reasons that lead us to attempt such an approximation are related to the contemporary geopolitical context and the simplification in the use of the concept of territory, for example, as a simple indicator of a space, over which one can apply methodologies, much of the time inspired by exogenous models of public policy. We conclude that the approximation to the concept of territory implies taking for granted the relational character of the articulations that occur in socio-political spaces built by social and governmental actors. Such a need becomes more relevant as one can observe the governmental initiatives that have been implemented at the federal level, which attempt to recuperate the ability to plan and promote development from the formation and articulation of national, regional and local public policies.
\end{abstract}

Key words: social networks; organizational networks; territory; public policies; development.

\footnotetext{
Artigo submetido em agosto e aceito para publicação em novembro de 2009.

${ }^{1}$ Doutora em Administração pela Universidade Federal de Pernambuco; Escola de Administração - Universidade Federal do Rio Grande do Sul, Endereço: Rua Washington Luiz, 855 - CEP 90010-460 - Centro - Porto Alegre - RS; E-mail: sueligoulart@ea.ufrgs.br .

2 Ph.D. em Administração, University of Edinburgh; Endereço: EBAPE/FGV - Praia de Botafogo, 190 - 5ํandar - Botafogo, CEP $22253-900$ - Rio de Janeiro - RJ / Brasil; E-mail: marcelo.vieira@fgv.br.

${ }^{3}$ Mestre em Administração pela Universidade Federal do Rio Grande do Sul; Universidade Federal do Pampa, Endereço: Rua Barão do Triunfo, 1048 CEP 97573-590 - Centro, Santana do Livramento - RS; E-mail: camilacfcosta@gmail.com .

${ }_{4}$ Mestre em Administração Pública pela EBAPE/FGV e Bacharel em Administração de Empresas pelo Observatório da Realidade Organizacional. Endereço: Praia de Botafogo, 190, 5ªndar, Rio de Janeiro-RJ; E-mail: knopp.glauco@gmail.com
} 


\section{Introdução}

Desde o início dos anos 1990 tem se assistido no Brasil à emergência da preocupação com a formação e implementação de políticas públicas alinhadas ao processo de descentralização preconizado pela Constituição Federal de 1988. As letras auspiciosas da Constituição brasileira, em seu artigo terceiro, afirmam como objetivos fundamentais da República Federativa a construção de uma sociedade livre, justa e solidária; a garantia do desenvolvimento nacional e a erradicação da pobreza e da marginalização, além da redução das desigualdades sociais e regionais (BRASIL, 1994).

Entretanto, o final da década de 1980 foi marcado também pela ascensão da ideologia neoliberal que, vitoriosa nos processos eleitorais no Brasil, uniu o discurso da redemocratização no campo da política ao da redução dos gastos públicos para resolver a crise fiscal e inflacionária, o que justificou a não priorização das reivindicações sociais. Segundo Cano (2007, p.25),

o neoliberalismo desencadeou profundo ataque ao Estado nacional, enfraquecendo-o nos vários planos de sua atuação. Uma das armas usadas foi a 'teoria do poder local', criando falsas idéias do desenvolvimento local, da cidade (ou da região) competitiva, emanadas de ações locais ou regionais.

Nesse contexto, a localidade passou a fazer parte da agenda de pesquisadores, de formuladores de políticas e dos governantes brasileiros. A área de administração não ficou fora desse movimento, inserindo o tema do poder local na agenda de pesquisa de grupos e de universidades. As pesquisas, nesse campo de estudos, foram operacionalizadas mediante investigações sobre formas organizativas e mecanismos ou modelos de gestão capazes de promover o desenvolvimento, predominantemente, baseado em formas organizacionais inovadoras e na articulação entre o Estado, o mercado e a sociedade.

Nas questões referentes à relação entre organizações e desenvolvimento, o que tem chamado nossa atenção é a vinculação à existência de formas organizacionais, tais como tais como redes, arranjos produtivos locais, cluster, consórcios e parcerias ao desenvolvimento das localidades. Muitos trabalhos na área de administração consideram que essas estruturas têm implicações diretas no desenvolvimento e que existem programas públicos, em todos os níveis de governo, que tanto utilizam esse tipo de estrutura como a incentivam. Porém, tem sido verificado que muito pouco se fala sobre o "local" onde essas redes atuam.

Partimos do pressuposto de que quando se fala em desenvolvimento local, estamos falando de um lugar territorialmente construído, isto é, de uma formação socioespacial onde os processos se efetivam. Sem consideração a territorialidade, o desenvolvimento local adquire o caráter, já indicado por Oliveira (2001, p.13), de um "emplastro [...] capaz de curar mazelas de uma sociedade pervertida, colocando-se no lugar de bucólicas e harmônicas comunidades". Como tal, serve a qualquer espaço e a qualquer grupamento humano, bastando, quando muito, que se identifique a vocação local para que, num voluntarioso ato de salvação, quaisquer atividades sejam valorizadas como potenciais econômicos.

Aqui, além do viés economicista - que vê quase exclusivamente o crescimento econômico, quando fala em desenvolvimento - repete-se em escala mais estrita a mesma noção das vantagens comparativas que engendrou, na periferia do sistema capitalista, o modo de assimilação indireta da civilização industrial, cujo resultado não é outro senão a perpetuação da estrutura centro-periferia; agora, como já se disse, em escalas mais estritas, como no âmbito de um país, de regiões, de estados, de microrregiões etc.

Entendemos que a exploração de construtos, conceitos e categorias de outras áreas disciplinares, particularmente da geografia, oferece importantes e consistentes elementos para a formação e para a investigação de políticas públicas direcionadas ao desenvolvimento. As razões que nos impelem a essa aproximação se relacionam tanto ao contexto geopolítico contemporâneo como à banalização de conceitos como território, por exemplo, usado como mero designativo de um espaço qualquer, sobre o qual se aplicam metodologias, muitas vezes, vinculadas a políticas públicas inspiradas em modelos exógenos. O que nos instiga é a possibilidade de contribuir para o engajamento da área de administração - particularmente, de gestão e políticas públicas - na abordagem da temática do desenvolvimento. 
É certo que uma reflexão profunda acerca da concepção de desenvolvimento é também extremamente necessária; entretanto, neste artigo, iremos nos dedicar à discussão das possibilidades no que se refere à aproximação da noção de território e de redes, explorando as categorias que podem apoiar estudos que contemplem a compreensão das relações entre as ações organizacionais e o espaço socioterritorial em que se inscrevem. Ainda que não tenhamos a pretensão, tampouco a possibilidade, de neste artigo nos aprofundarmos na discussão sobre a concepção de desenvolvimento, é certo que o exercício teórico que tentaremos empreender estará, a todo o momento, dela se acercando.

Para situarmos o contexto vislumbrado, a partir do qual faremos o exercício teórico de aproximação, inicialmente discutiremos a inserção da localidade e das organizações em rede na formação de políticas públicas para o desenvolvimento. Em seguida, será apresentada e discutida a abordagem de território e dos acontecimentos decorrentes das articulações em rede. Depois, serão apresentadas algumas políticas de desenvolvimento loco-regionais e de ordenamento territorial formuladas e implementadas no Brasil, seguindose então as considerações finais deste artigo.

\section{A localidade e as organizações em rede: as políticas públicas voltadas para o desenvolvimento}

As primeiras experiências com planejamento visando ao desenvolvimento no Brasil emergiram no contexto da II Guerra Mundial (1939-1945), quando o Estado organizou-se para administrar recursos e suprir contingenciamentos, através de planos de longo prazo. As políticas desse período se caracterizavam mais pela necessidade de organizar os gastos públicos do que efetivamente por um planejamento completo, principalmente, devido às dificuldades financeiras geradas pela falta de investimento externo (BRASIL, [2004?]).

O período compreendido entre os anos 1950 e 1980 foi marcado por forte intervenção estatal, centralismo na esfera federal e restrita participação da sociedade civil nas decisões sobre investimentos em projetos de desenvolvimento. Os pesados investimentos em infraestrutura, energia, transporte e comunicação, mesmo localmente alocados, faziam parte de um processo de divisão nacional do trabalho em que cada região tinha uma função predefinida no desenvolvimento do país.

Além do centralismo na esfera federal, Bacelar (2006) aponta o viés autoritário como outra forte característica, reflexo do longo período de ditadura (1964-1985), intercalado com poucos períodos de democracia. Assim, as políticas públicas de desenvolvimento em nível local eram formuladas de cima para baixo, com base no planejamento nacional e na centralização decisória e financeira na esfera federal. Farah (2001) acrescenta que elas possuíam como característica a fragmentação institucional; ou seja, não havia articulação tanto no mesmo nível como em níveis diferentes de governo.

No processo de formulação, implementação e controle das políticas públicas havia, portanto, exclusão da sociedade civil. As políticas sociais funcionavam basicamente influenciadas por três características: pelo clientelismo, pelo corporativismo e pelo isolamento burocrático. Dessa forma, havia um padrão nãodemocrático de articulação entre Estado e sociedade, com ampla exclusão de segmentos sociais no que se refere ao acesso a bens e serviços públicos (FARAH, 2001).

O processo de redemocratização do país, a partir dos anos 1980, modificou essa estrutura. A equidade dos resultados nas políticas sociais passou a ser fator-chave no entendimento da democratização, visto que era uma condição para tal (FARAH, 2001). As políticas públicas de desenvolvimento também passaram por um processo de democratização e descentralização, sendo adotados os conceitos de participação e de articulação entre os atores sociais no seu processo de formulação e implementação.

No inicio da década de 1990 procurou-se, portanto, adicionar à agenda democrática, novos ingredientes orientados pela busca da eficiência, da eficácia e da efetividade na ação estatal (FARAH, 2001). Tais ingredientes seriam novas formas de articulação do poder público com a sociedade civil e a iniciativa privada, buscando a garantia da prestação de serviços, assim como a construção de novas modalidades de solidariedades 
(LIPIZETZ apud FARAH, 2001). O Estado passaria, então, de provedor único para coordenador e fiscalizador de serviços providos pela sociedade civil, pelo mercado ou por parcerias com estes setores.

Nos anos 1990, também foram incorporadas no processo de planejamento escalas de regionalização, sendo as macrorregiões divididas em sub-regiões, áreas-programa e áreas de desenvolvimento local, com a finalidade de definir programas governamentais mais adequados às especificidades de cada segmento do espaço regional. $\mathrm{O}$ espaço macrorregional foi considerado muito extenso geograficamente e com características econômicas e físicas muito heterogêneas, dificultando a atuação do governo (BRASIL, [2004?]).

Sob essas justificativas, percebe-se uma revalorização do território como uma dimensão espacial do processo de desenvolvimento, mas também o risco de banalização de questões "que, malgrado sua natureza estrutural, histórica e dinâmica, foram deslocadas para o lugar-comum do voluntarismo, cristalizando um grande consenso, um verdadeiro "pensamento único localista"' (BRANDÃO, 2007, p.36). Brandão (2007) afirma que esse discurso produziu farta literatura e promoveu a implementação de políticas públicas orientadas, em parte ou totalmente, por essa concepção, ocupando a agenda da academia e dos governos estaduais e municipais.

À falta de um projeto nacional de desenvolvimento, os agentes locais assumiram a responsabilidade de promover e de incentivar o desenvolvimento, tanto em escala regional como estadual e municipal. Bacelar (2006, p.383) registra esse movimento, afirmando que "em muitas áreas do país, agentes locais têm-se articulado para pensar e propor estratégias de desenvolvimento local e regional". Muitas das iniciativas estavam voltadas para o incentivo à formação de redes, entre atores sociais (individuais ou coletivos) e atores governamentais ou somente entre atores sociais, visando inserir as regiões na economia globalizada.

Diante das inúmeras ações dos governos, dos atores locais e das organizações sociais, bem como da crescente articulação entre eles, tem se reforçado o interesse da administração pelas questões referentes ao desenvolvimento e, particularmente, sobre as formas organizacionais como estruturas fomentadoras desse processo.

Para Goulart (2006, p.2)

o crescente interesse dos pesquisadores da área de Administração pela temática do desenvolvimento contribui para ampliar as discussões a respeito das relações entre organização e ambiente, dos efeitos concretos das ações organizacionais no mundo da vida.

Nesse sentido, muitos pesquisadores têm buscado apreender o conceito de desenvolvimento local para um melhor entendimento das relações com o universo organizacional, incluindo as formas organizativas.

O desenvolvimento, tão amplamente discutido pela academia, tanto no Brasil quanto no exterior, e com forte presença na agenda governamental de diversos países, diz respeito a um conceito complexo. É abordado de forma multidimensional, ou seja, recusando-se o viés estritamente econômico, sendo visto também na sua dimensão social, política, humana, cultural e ambiental. Pode-se ainda atribuir ao conceito de desenvolvimento adjetivos referentes à escala espacial em que ocorre, tais como local, regional, nacional e global, entre outros.

Segundo Fischer (2002, p.17) "desenvolvimento é um conceito, ou melhor, uma rede de conceitos que podem estar diretamente associados como, atualmente, aos adjetivos local, integrado e sustentável". A autora complementa que não há como falar em desenvolvimento local sem menção a conceitos como pobreza e exclusão, participação e solidariedade, além de produção e competitividade, entre outros que se articulam e reforçam mutuamente ou que se opõem frontalmente.

Na concepção de Buarque (1999), desenvolvimento local é um processo endógeno atrelado às pequenas unidades territoriais e aglomerações humanas capazes de promover o dinamismo econômico e a melhoria da qualidade de vida da população. O autor complementa que o desenvolvimento é resultado da mobilização das energias da sociedade, buscando explorar suas capacidades e potencialidades, além de representar uma singular transformação nas bases econômicas e na organização social em nível local. 
Apesar de constituir um movimento de forte conteúdo interno, o desenvolvimento local está inserido em uma realidade mais ampla e complexa, com a qual interage e da qual recebe influências e pressões positivas e negativas. Dentro das condições contemporâneas de globalização e intenso processo de transformação, o desenvolvimento local representa também alguma forma de integração econômica com o contexto regional e nacional. (BUARQUE, 1999)

Oliveira (2001), tomando como base o conceito estabelecido pela Organização das Nações Unidas (ONU), considera que desenvolvimento local é a satisfação de um conjunto de requisitos de bem-estar e qualidade de vida, num âmbito mais restrito. Para o autor, o desenvolvimento deve ser compreendido em duas dimensões: a primeira refere-se à especificidade histórica, visto que está atrelado à periferia do capitalismo, ao nãodesenvolvimento local ou ao subdesenvolvimento; a segunda refere-se à noção de cidadania, dado que o desenvolvimento local é resultado de indivíduos autônomos, críticos e reflexivos, não de uma mera acumulação, dissociada do conflito. Porém, segundo Oliveira (2001, p.24) "o desenvolvimento local tende a substituir a cidadania, tende a ser utilizado como sinônimo de cooperação, de negociação, de completa convergência de interesses, de apaziguamento de conflitos".

Nos estudos que vinculam arranjos organizacionais ao desenvolvimento local são numerosos os trabalhos que consideram as parcerias, consórcios, arranjos produtivos locais e outras formas de variações interorganizacionais como configurações capazes de promover desenvolvimento local (GOULART, 2006). Essas formas organizacionais são incentivadas mediante a justificativa de que são estruturas adequadas para gerar desenvolvimento no contexto do mundo globalizado. Além disso, elas possibilitam não apenas desonerar o Estado do papel de principal promotor do desenvolvimento, garantidor da sobrevivência e da competitividade (principalmente) das pequenas e médias empresas, mas também resgatar identidades e vocações locais. Esses arranjos podem ser justificados, ainda, por comportarem a articulação entre diversos atores - abrindo espaço para a participação da sociedade civil em decisões sobre investimentos governamentais e/ou na elaboração de políticas públicas - e por constituírem espaços profícuos para inovações, igualmente valorizados como diferencial competitivo (GOULART, 2006).

Genericamente tratados como redes (apesar da ambiguidade desse conceito), esses arranjos organizacionais ganharam espaço significativo nas políticas definidas como de desenvolvimento local. O termo "rede" vem do latim retis, significando o entrelaçamento de fios com aberturas regulares que formam uma espécie de tecido. A partir da noção de entrelaçamento, malha e estrutura reticulada, foi ganhando novos significados ao longo do tempo, passando a ser empregado em diferentes situações (OLIVIERI, 2008).

Segundo Loiola e Moura (1996, p.53),

chama a atenção a crescente utilização do conceito de rede no campo das ciências sociais. Como na linguagem cotidiana, todavia, esse conceito vem sendo empregado com diferentes sentidos, denotando muitas vezes noções aparentemente contraditórias.

A multiplicidade de conceitos é verificada nas diversas áreas que o utilizam.

Uma das referências recorrentes a todas as áreas é a obra A sociedade em rede, do sociólogo Manuel Castells. Para ele, o desenvolvimento das tecnologias de informação e a necessidade de reestruturação do capitalismo foram os dois aspectos fundamentais na emergência de uma sociedade em rede. Embora não sejam os únicos, esses fatores desencadearam uma nova lógica organizacional de desenvolvimento (CASTELLS, 1999).

Para Dias (2003), a densificação das redes surge como condição que se impõe para a circulação de tecnologia, de capitais e de matérias-primas. Segundo a autora, as redes são instrumentos que possibilitam colocar em prática as estratégias de circular e comunicar. As redes, no entendimento de Viera e Vieira (2004), proporcionam a interconexão de fluxos de riqueza e poder. Elas, na economia global, são estruturas determinantes da produtividade, juntamente com a tecnologia, a estrutura organizacional e o gerenciamento. Para Radamsky e Schneider (2007), as redes tornaram-se a imagem e a representação emblemática dos 
processos sociais globalizados. As redes, portanto, fundamentam uma forma de organização para a economia global.

Assim, busca-se categorizar os estudos sobre redes nas análises organizacionais. Loiola e Moura (1996) ampliam a noção, atribuindo o conceito de campo aos estudos das redes. As autoras consideram a existência de quatro campos: o campo das relações pessoais, dos movimentos sociais, do Estado e o campo empresarial. A análise desses campos situa-se na dimensão das relações entre agentes e, consequentemente, nas formas de organização da sociedade.

No campo das relações pessoais, as redes são estudadas com foco no indivíduo. São conceituadas com base nas interações estabelecidas com objetivos de comunicação e de ajuda mútua, a partir de interesses comuns. Essas redes são estruturas informais, estabelecidas ao longo do tempo pela articulação dos atores com objetivos profissionais ou por laços culturais e sociais.

No campo dos movimentos sociais, a rede corresponderia a articulações entre organizações, grupos e indivíduos vinculados a movimentos de reivindicação, buscando mobilização de recursos, troca de informações e experiências, assim como a formulação de políticas públicas. As redes seriam determinantes no processo de mobilização, visto que os movimentos sociais são compostos de inúmeras relações informais. Assim, as redes de solidariedade poderiam, através de uma complexa articulação entre os agentes locais e externos, adquirir status mundial, como efetivamente ocorre na presente ordem global.

No campo dos negócios, as redes representam uma organização intermediária entre as unidades de produção e o mercado. Para Castells (1999, p.183), a organização em rede surge como uma forma intermediária de combinação entre "a desintegração vertical por meio dos sistemas de subcontratação de uma grande empresa e as redes horizontais das pequenas empresas". Viera e Vieira (2004) afirmam que as redes estratégicas de empresas contribuíram para a adoção da flexibilidade organizacional. As empresas utilizariam as redes estratégicas com a finalidade de garantir flexibilidade e concorrência nos espaços de consumo.

Uma das constatações nesse campo é que a adoção das redes como estruturas organizacionais é o resultado da crise do modelo corporativo tradicional, fundamentado na integração vertical e no gerenciamento funcional hierárquico. Ao serem observados os antecedentes históricos do modo fordista de produção (inflexibilidade e economia de larga escala) e do modo toyotista de produção (qualidade total, flexibilização do processo e cooperação gerente-trabalhador), constatou-se que não somente a flexibilização do processo e do produto, mas também a flexibilização geográfica seria mais vantajosa em diversas instâncias (CASTELLS, 1999).

Para Castells (1999, p.498), "rede é um conjunto de nós interconectados" com grande flexibilidade para lidar com a complexidade das sociedades contemporâneas, sob o paradigma informacional.

[...] redes são estruturas abertas capazes de se expandir de forma ilimitada, integrando novos nós, desde que consigam comunicar-se dentro da rede, ou seja, desde que compartilhem os mesmos códigos de comunicação (por exemplo, valores ou objetivos de desempenho). Uma estrutura social com base em redes é um sistema aberto altamente dinâmico, suscetível de inovação, sem ameaças ao seu equilíbrio. (CASTELLS, 1999, p.499)

Muitos são os estudos que tratam de redes estratégicas ou redes de empresas. Na concepção de Baum e Ingram (2000), as redes interorganizacionais podem ser divididas em duas classes de análise: redes verticais e redes horizontais. As primeiras envolvem a articulação de atividades de fornecedores e distribuidores por uma empresa coordenadora, a qual exerce considerável influência sobre as ações dos outros agentes que integram a cadeia produtiva. Já as redes horizontais são compostas por empresas similares que se associam na busca por fins coletivos, como ocorre em consórcios de pesquisa e em associações comerciais. Para Pereira (2005) as redes horizontais podem ser definidas como interações sociais que envolvem um grupo de empresas buscando interesses comuns, que requerem ações conjuntas e que podem ser realizadas coletivamente, mas não individualmente. Assim, as redes horizontais pressupõem relações de interdependência, de cooperação e de harmonia na resolução dos conflitos, bem como menor uso do poder formal (PEREIRA, 2005). 
Como exemplos apontam-se as redes de pequenas e médias empresas (PMEs), consideradas redes horizontais, definidas por Balestrin e Vargas (2002, p.11) como um grupo constituído intencionalmente por empresas. Esse arranjo tem as seguintes características, que as distingue das demais relações interorganizacionais:

a) as redes de PMEs são geralmente criadas para fornecer um fórum direto de atividade e relações entre os seus membros. Os membros permanecem independentes, mesmo trabalhando em atividades conjuntas. Os atores dessas redes perseguem objetivos comuns por meio de interações coordenadas de dez, vinte ou mais firmas individuais [...];

b) as redes de PMEs promovem complexas e recíprocas interdependências nas quais os seus membros fornecem inputs e recebem outputs uns dos outros. Essas inter-relações são usualmente coordenadas pelas próprias firmas da rede. Esses mecanismos de coordenação são geralmente informais e facilitados pela própria dinâmica de interação entre os membros [...];

c) o critério de participação em uma rede de PMEs enfatiza a proximidade geográfica pela qual as firmas membros combinam competências centrais para o alcance de objetivos organizacionais comuns, que de forma individual não alcançariam [...] (HUMAN; PROVAN, 1997 apud BALESTRIN; $\operatorname{VARGAS}(2002, p .11)$.

Além dessas características, outro aspecto relacionado à tipologia de rede de PMEs, de acordo com Perrow apud Balestrin e Vargas (2002), é a infraestrutura essencial para sua sobrevivência e para sua economia, a qual abrange: incentivos de governos locais e regionais, serviço educacional, além de associações comerciais que fornecem informação econômica, treinamento e serviços de marketing. Para o autor, esse ambiente, usualmente encontrado nos distritos industriais italianos, contribui significativamente para o desenvolvimento de regiões e para o próprio crescimento das PMEs. O papel do Estado na formação dessas redes introduz o quarto campo do estudo das redes proposto por Loiola e Moura (1996): o campo do Estado. Neste, as redes são formas de articulação entre agências governamentais e entre estas e redes sociais - incluindo também atores privados -, com a finalidade de construir políticas públicas. Isso se dá por meio de assessoramento técnico, linhas de crédito e incentivos fiscais, além de representação participativa.

As redes institucionais (ou redes sociogovernamentais) surgiram como resultado do processo de reforma da administração pública, exigindo dos órgãos governamentais eficiência e eficácia na prestação dos serviços. No campo do Estado, a área da saúde pública foi uma das pioneiras na articulação em redes interorganizacionais, particularmente, em razão do modelo de gestão implantado com o Sistema Único de Saúde (SUS).

Misoczky (2001) abordou tais redes como arranjos de gestão alternativos à hierarquia na formação de políticas públicas de atenção à saúde, visando maior equidade nos resultados das políticas. A autora entende as redes como "processos de formação de políticas públicas que envolvam múltiplos nós (organizações) com múltiplas conexões" (MISOCZKY, 2001, p.348). Destaca ainda que a adoção de redes pela administração pública se reveste de um caráter político, já que alterariam as relações de poder e as relações entre a sociedade e a administração pública, visto que estariam centradas na cooperação através da parceria e não na hierarquia.

Ainda no âmbito da gestão pública, alguns autores, destacam o papel do Estado no incentivo à ampliação do potencial competitivo das pequenas e médias empresas, mediante a proposição de uma política de desenvolvimento regional que contemple a formação de redes interorganizacionais (AMATO, 2000, BARQUEIRO, 2001; CÂNDIDO, 2002; VERSCHOORE, 2006). Algumas dessas redes conduzem também à formação de consórcios de exportação apoiados pelo Estado.

Barquero (2001) afirma que um dos elementos centrais na busca por definir uma estratégia de desenvolvimento local é a capacidade da cidade ou região de ampliar a cooperação entre os agentes e instituições, por meio de ações que possibilitem a criação e o desenvolvimento de redes de atores privados e instituições. Funcionalizadas ao atual momento do capitalismo, as redes promoveriam a propalada articulação global-local.

Ainda que bastante disseminadas como mecanismo de articulação funcional a projetos de desenvolvimento, as redes são abordadas predominantemente em seus aspectos estruturais, e, assim, sem maiores conexões com o 
espaço de vida em que se inserem ou mesmo com as necessárias conexões escalares, em tempos de globalização. Argumentamos que ao inserir o tema das organizações em rede articuladas a políticas públicas voltadas para o desenvolvimento, é preciso considerar, sempre, a natureza da formação socioespacial e o caráter transversal de suas ações; ou seja, a conexão articulada entre as escalas local e global.

Na próxima seção, iremos explorar conceitos da geografia para ampliarmos o olhar sobre a dimensão territorial do desenvolvimento e as implicações das articulações entre atores sociais e governamentais. Isto é, buscaremos elementos teóricos que ofereçam embasamento para a análise de acontecimentos produzidos pela articulação entre atores sociais e governamentais no território. Nossa expectativa é delinear um arcabouço preliminar que contribua para o aprofundamento de estudos acerca das relações entre organizações, formação de políticas públicas, desenvolvimento e território.

\section{A produção de acontecimentos no território}

Tendo em vista o pressuposto de que ao se falar de desenvolvimento local se esteja referindo a um lugar de vida, e sede de atividade econômica, consideramos necessário compreender as bases de assentamento dos grupamentos humanos e a formação socioespacial em que ocorrem as interações. Inicialmente, é fundamental distinguir espaço de território.

Segundo Raffestin (1993), o espaço vem antes do território; ou seja, o território é formado a partir do espaço, em função da ação de um ator sintagmático (aquele que realiza determinadas ações) em diferentes níveis. Ao se apropriar de um dado espaço, de forma concreta ou abstrata, o ator "territorializa" o espaço. Eduardo (2006, p.178), por sua vez, interpreta que "o território consiste em uma produção a partir do espaço e [que] esta se cristaliza através da produção social do espaço por atores que realizam determinadas atividades sociais".

O território "é um espaço onde se projetou um trabalho [que] se apoia no espaço, mas [que] não é o espaço. É uma produção, a partir do espaço. Ora, a produção, por causa de todas as relações envolvidas, se inscreve num campo de poder" (RAFFESTIN, 1993, p.144). Portanto, para Raffestin (1993), é por meio do trabalho que os atores se apropriam do espaço e o territorializam. O território, nesse sentido, revela relações econômicas e de poder.

Outro conceito importante dos estudos de Raffestin (1993) é a noção de sistema territorial como fruto de relações de poder do Estado, de empresas e outras organizações e de indivíduos. Trata-se de relações diárias, ligadas à dinâmica política econômica e cultural, que constituem malhas (conjunto de pontos e ligações/conexões entre diferentes agentes sociais), nós (pontos de encontro de relações sociais) e redes (ligações entre dois ou mais agentes sociais). Na concepção do autor, os atores sociais efetuam a repartição da superfície, a implementação dos nós e a construção das redes, sendo os sistemas territoriais aqueles que permitem a coesão dos territórios e o controle de pessoas e coisas. Segundo Giuseppe Dematteis, cada sistema territorial local possui aspectos ambientais e uma construção social histórica, econômica, política e cultural, processual e relacional, na qual se estabelece uma organização, no sentido de coesão e de projeção do futuro (SAQUET, 2007).

Para Rullani (apud SAQUET, 2007, p.105), o território é caracterizado como enraizamento, identidade, conexão, recursos ambientais, relações cotidianas, experiências e lugar de vida, onde a territorialização se dá, fundamentalmente, por aspectos econômicos e culturais. "O território é um lugar particular (local) e, ao mesmo tempo, um nexo entre aquele lugar e todos os outros possíveis lugares (global)". No território transformado em nacionalidade, o lugar local é o produto da herança histórica e como tal transporta os simbolismos inerentes. Parte do território pode formar lugares globais na dimensão transterritorial: são os espaços econômicos fragmentados.

Saquet (2007), ao tratar de território, natureza e desenvolvimento local, apresenta, como uma tendência, a abordagem híbrida e relacional, iniciada a partir da obra de Dematteis. "Este se mostra preocupado com a combinação de relações geográficas verticais e horizontais, com as condições e com as articulações territoriais 
para o desenvolvimento" (SAQUET, 2007, p.112). Ele "aborda a importância de relações entre o endógeno e o exógeno em processos de desenvolvimento local" (SAQUET, 2007, p.112). A importância da reciprocidade entre território e sociedade é evidenciada pelo autor. Para ele, nada se pensa que não seja através da materialidade dos lugares, inclusive, como componente da totalidade das relações sociais.

A partir dessa perspectiva, Dematteis, juntamente com Raffestin, define as territorialidades como um fenômeno social, envolvendo indivíduos que fazem parte de grupos interagindo entre si, mediadas pelo território; mediações estas que mudam no tempo e no espaço. As territorialidades dependem da existência de relações intersubjetivas; em última instância, dependem da existência da redes locais que ligam o espaço local aos espaços globais, interagindo com a natureza. Assim, o agir social é territorial, é local, e as redes de sujeitos são um instrumento conceitual para governar a territorialidade (SAQUET, 2007).

Dematteis (2005 apud SAQUET, 2007, p.120) considera que "o desenvolvimento está ligado sempre, de algum modo, com a dimensão local", observando que este "efetiva-se na relação entre o local e o universal". Nesse sentido, cabe aqui também destacar as reflexões que remetem às relações entre infraestrutura e território como redes, tratando-as como:

produtos de um contexto, condicionando-o na forma de um acoplamento, [conforme] Dematteis (1995 e 1996): a relação infraestrutura/território aparece como um processo de interação entre o local e o global. Interconexões e territorialização são dois processos coligados. Há reterritorização, através das conexões efetuadas com as redes: os diversos sujeitos locais se reterritorizam em diversas redes (SAQUET, 2007, p.120).

Há de entender-se, contudo, na presente ordem econômica global, que o desenvolvimento tem sua face transterritorial, da qual emergem produção e poder. É a versão global da economia em conformações geográficas de alianças estratégicas ou blocos econômicos. O desenvolvimento global pode ter sede em um determinado lugar local, transformando-o em lugar global; a fragmentação da produção, o poder e o consumo são transterritoriais. Nesse caso, há uma desterritorialização de parte do território do Estado-nação. A circulação de fluxos de demanda e poder, informação e conhecimento independem de fronteiras físicas, o que, de alguma maneira, afeta as práticas que deram origem ao território como representação simbólica de uma nacionalidade. A transterritorialidade de eventos econômicos, sociais e culturais é dependente dos enlaces que se sustentam nas tecnologias da informação. A evolução nessa área é permanente e acelerada, certamente, impactando a produção das relações em rede.

Para Raffestin (1993, p.207), “a rede é por definição móvel no quadro espaço-temporal”; é inacabada. É “dessa falta de acabamento que ela tira sua força no espaço e no tempo: se adapta às variações do espaço e às mudanças que advêm do tempo" (RAFFESTIN, 1993, p.204). É um sistema de fluxos, de circulação, e desse ponto de vista está em perpétua transformação.

As redes dependem dos atores que controlam os seus pontos, "da posição relativa que cada um deles ocupa em relação aos fluxos que [nelas] circulam" (RAFFESTIN, 1993, p.207). Esses fluxos são produzidos, de forma variável, por atores em função de seus projetos políticos e econômicos. As redes se configuram, portanto, como um instrumento por excelência do poder.

Ao falarmos de rede, é preciso ter claro que não se trata de um sistema de linhas e nós com configuração única e imutável. No âmbito da economia global, destacam-se algumas configurações de redes: "redes espaciais de produção; as redes de montagem globais; as redes de distribuição globais; as redes financeiras globais; as redes de telecomunicações e a internet; e as redes globais do crime organizado" (VIEIRA; VIEIRA, 2003, p.57). Para Santos (2006, p.268) "onde as redes existem, elas não são uniformes. Num mesmo subespaço, há uma sobreposição de redes [...]".

Santos (2006, p.270 e 279) caracteriza as redes como "um veículo de movimento dialético" que confronta, ao mesmo tempo em que une, o global e o local, criando, paralelamente, ordem e desordem no território, já que "integram e desintegram, destroem velhos recortes espaciais e criam outros". São, simultaneamente, 
"concentradoras e dispersoras, condutoras de forças centrípetas e de forças centrífugas" (SANTOS, 2006, p.278). Elas revelam, então, a superposição de vários sistemas lógicos, a mistura de várias racionalidades:

As redes são, ao mesmo tempo, globais e locais. São globais porque cobrem todo o ecúmeno e, na verdade, constituem o principal instrumento de unificação do Planeta. Mas elas também são locais, já que cada lugar, através de sua estrutura técnica e de sua estrutura informacional, acolhe uma fração, maior ou menor, das redes globais. No lugar, elas servem ao trabalho e ao capital (vivo) e determinam a sua natureza. (SANTOS, 1999, p.14)

As redes globais são caracterizadas por geoestratégias transterritoriais, por trocas recíprocas dentro de um sistema policêntrico, cuja ação se estende além dos limites geográficos do local onde um determinado ator se estabelece e emite fluxos decisórios (CONTI, 2005). As redes locais são caracterizadas por relações entre agentes autocontidos em um dado lugar. Essas relações podem ser explicadas não apenas em termos de proximidade geográfica entre os atores e territórios, mas também pela sua imersão em um contexto econômico, cultural e social específico (CONTI, 2005). Ao mesmo tempo, as redes de relações locais podem interagir com outros níveis territoriais e redes, por meio de atores que pertençam simultaneamente a uma ou mais redes locais e a uma ou mais redes globais.

Desse modo, a partir da dialética territorial, conforme Santos (1998, 2000, 2006), são identificados novos recortes no território, decorrentes do processo de globalização, os quais esse autor classificou de horizontalidades e verticalidades. São dois cortes simultâneos e complementares do espaço geográfico. Na verdade, são as fragmentações do espaço, suas funcionalidades e reordenações dos lugares em continuidades geográficas ou não.

Horizontalidade diz respeito aos lugares geograficamente próximos, reunidos por uma continuidade territorial. Nesse sentido, Santos (2000, p.108) afirma que as "horizontalidades são zonas da contiguidade que formam extensões contínuas", observando tratar-se de "extensões formadas de pontos que se agregam sem descontinuidade" (SANTOS, 2006, p.284 e 259), que levam em conta "a totalidade dos atores e das ações" e geram uma coesão posta a "serviço da sociedade civil como um todo". Portanto, horizontalidade significa tanto as articulações quanto os benefícios gerados no âmbito local pelas ações de um determinado ator sobre o território onde se instala. Ela gera as chamadas forças centrípetas, que

resultam do processo econômico e do processo social, [os quais] tanto podem estar subordinados às regularidades do processo de produção, quanto às surpresas da intersubjetividade. Essas forças centripetas, forças de agregação, são fatores de convergência (SANTOS, 2006, p. 284).

Verticalidade é definida como "um conjunto de pontos formando um espaço de fluxos" (SANTOS, 2000, p.105) num território, remontando à ideia de espaço econômico. É constituída por "pontos no espaço que, separados um dos outros, asseguram o funcionamento global da sociedade e da economia" (SANTOS, 2006, p.284). Nesse sentido, refere-se às finalidades e ações impostas de fora, de longe e de cima sobre um determinado território. É inerente à ordem global, pois "funda as escalas superiores ou externas à escala do cotidiano" (Ibidem, p.339). São movidas por forças centrífugas, ou seja, forças de fragmentação e desagregação da base territorial (GOULART, 2006). São assim consideradas porque "retiram à região os elementos do seu próprio comando, a ser buscado fora e longe dali" (SANTOS, 2006, p.286-87). Ou seja, as verticalidades e as forças delas decorrentes, centrífugas, usufruem do território como um recurso a ser explorado, a partir do uso pragmático de seu conjunto de equipamentos, instituições, práticas e normas (SANTOS, 2000).

As verticalidades, portanto, são criadas por meio da coesão organizacional baseada em racionalidades de origens distantes. Criam amplas interdependências entre lugares dispersos pelo planeta, mas integrados sob a forma de redes globais. Essa interdependência tende a ser hierárquica e realizada por meio de ordens técnicas, financeiras e políticas, ditadas por atores e países hegemônicos globais, gerando uma integração dependente e alienadora dos lugares locais ao sistema econômico mundial, uma vez que "as decisões essenciais concernentes aos processos locais são estranhas ao lugar e obedecem a motivações distantes" (SANTOS, 2000, p. 106). "As verticalidades são vetores de uma racionalidade superior e do discurso pragmático dos setores hegemônicos, 
criando um cotidiano obediente e disciplinado" (SANTOS, 2006, p.286). Também resultam da evolução da atividade econômica, em nova fase, motivada pelas transformações tecnológicas da atualidade. A tendência é de ampliação das verticalidades, tanto no plano virtual como no plano real.

A fluidez informacional produzida pelas novas tecnologias de informação e comunicação garante sustentação às verticalidades virtuais. A disponibilidade de recursos internacionais - principalmente, de conhecimento e informação - aos países e regiões com menor ritmo de desenvolvimento, direcionados ao estabelecimento de segmentos produtivos e acadêmicos, concretiza a funcionalidade dos lugares e das redes em relação ao processo de desenvolvimento. No entanto, os lugares e os atores sociais governamentais também podem fortalecer as horizontalidades, "reconstruindo, a partir das ações localmente constituídas, uma base de vida que amplie a coesão da sociedade civil, a serviço do interesse coletivo" (SANTOS, 1997, p. 227). A sobreposição dos recortes e a simultaneidade das forças criam, na visão de Santos (1998, p.16) "novas solidariedades", a despeito de diferenças entre pessoas ou lugares.

As "novas solidariedades" têm como elemento central a informação que adquiriu, ao longo do tempo, capacidade de reunir diferentes porções de um território. Para o autor supracitado, as "novas solidariedades" podem ocorrer sob três diferentes formas: homóloga, complementar ou hierárquica. A homologia diz respeito às áreas de produção modernizadas e confluentes em função de uma informação especializada que, presidindo a racionalidade, cria similitude de atividades e gera contiguidades funcionais. A complementaridade se refere à articulação entre diferentes atividades, que se estabelecem igualmente em decorrência da modernização produtiva e da necessidade de intercâmbio geograficamente próximo. A forma hierárquica, como resultado da crescente racionalização das atividades, ocorre sob comando tendencialmente concentrado num agente ou numa organização que, independentemente de sua localização, interfira no espaço socioterritorial.

Sob as duas primeiras formas, o sentido, o cotidiano é compartido mediante regras estabelecidas ou reformuladas no âmbito local. Nesse caso, a informação tende a se generalizar, ou seja, tende ao domínio coletivo local. Sob a forma hierárquica, é estabelecido um cotidiano imposto externamente, comandado por informação privilegiada, secreta e que se caracteriza como importante recurso de poder (SANTOS, 1998).

Num exercício de conexão dessas categorias com o desenvolvimento, Goulart (2006, p.13) conjecturou que as horizontalidades "conjugam ações e atividades que atravessam o território, que se espraiam por ele". São formas de articulação que podem induzir transformações sociais direcionadas à homogeneização social, que não se restringe meramente à uniformização dos estilos de vida ou do consumo, indo ao encontro das concepções de Furtado (2000). A forma hierárquica, ao contrário, restringir-se-ia a

modernizar o estilo de vida de segmentos da população, ou seja, daqueles capazes de consumir a última técnica, a última moda. Se privilegiadas na formulação das políticas voltadas para o desenvolvimento, ainda que dito local, aprofundam a heterogeneidade social no território. (GOULART, 2006, p.7)

Assim, os acontecimentos produzidos no território, entendidos a partir das relações de poder que engendram e nos quais estão, simultaneamente, engendrados, oferecem categorias importantes de análise para o entendimento das bases de formação, sustentação e avaliação de políticas públicas voltadas para o desenvolvimento. Entretanto, é importante ressaltar que não podem mascarar a dimensão macroestrutural do desenvolvimento. Como lembra Oliveira (2001), o desenvolvimento, embora local, não representa um elo numa cadeia de desenvolvimento total - mas busca corrigir a tendência de concentração que parece inerente ao processo capitalista - embora também possa tornar-se inteiramente funcional ao sistema. Nesse aspecto, também as formulações da geografia, particularmente, de Milton Santos, podem ser bastante significativas, apontando alternativas para a formulação de políticas públicas nacionais voltadas ao desenvolvimento socioterritorial, pautadas pelas especificidades, potencialidades e demandas locais. Em outra visão, o desenvolvimento local é parte do projeto de desenvolvimento nacional, inserindo-se, necessariamente, no desenvolvimento global. Essa inserção, contudo, será qualitativa, na medida da escala do desenvolvimento endógeno. 


\section{As políticas de desenvolvimento loco-regional e de ordenamento territorial no Brasil}

O maior desafio contemporâneo das políticas públicas brasileiras é tentar consolidar a "descentralização coordenada", considerando as múltiplas escalas e evitando a descentralização atomizada (BACELAR, 2006). Esse alerta, bastante atual e pertinente, pode ser traduzido para a área de administração - particularmente de gestão e políticas públicas - como a necessidade de ampliar os horizontes, no que se refere ao entendimento da relação entre organizações e desenvolvimento, notadamente, quando se concentra em discussões sobre formas reticulares como portadoras de alto potencial de influência sobre esse processo.

O caráter marcadamente funcionalista das abordagens de redes nos estudos organizacionais restringe muitos estudos a aspectos estruturais das redes, concentrando investigações em elementos como governança, controle, resultados, metodologias, possibilidades de replicação de experiências etc. A aproximação à concepção de território aqui apresentada indica a necessidade de assumir o caráter relacional das articulações que ocorrem em espaços sociopolíticos construídos por atores sociais (individuais e coletivos) e por atores governamentais. Essa visão reforça a natureza das relações que se desenvolvem nos espaços social, econômico e político do território.

Essa necessidade é tanto mais relevante quanto mais se observam iniciativas que vêm sendo encaminhadas no plano federal, no sentido de se recuperar a capacidade de planejamento e promoção do desenvolvimento mediante a formação de políticas públicas de âmbito nacional.

Em 2003, o governo federal iniciou a implantação de um novo modelo de desenvolvimento econômico e social, cujos pressupostos incluem combinar crescimento da economia com distribuição de renda, criação de emprego e melhoria das condições de vida da população brasileira. Um dos eixos desse novo modelo foi o Programa de Gestão da Política de Desenvolvimento Regional e Ordenamento Territorial, atendendo aos preceitos estabelecidos no artigo 21, parágrafo IX da Carta Magna: "Compete à União elaborar e executar planos nacionais e regionais de ordenação do território e de desenvolvimento econômico e social". O objetivo desse programa é

articular as ações de instituições federais, estaduais e locais na implementação das políticas de desenvolvimento regional e ordenamento territorial, a fim de buscar a redução das desigualdades regionais e promover a ativação dos potenciais da rica diversidade econômica e social do território. $O$ planejamento e a implementação dessas ações são orientados conforme as escalas territoriais nacional, macrorregional, messorregional, microrregional e intraurbana. (BRASIL, [2004?])

No referido programa é possível constatar uma preocupação substancial com a diversidade e as desigualdades existentes no território nacional. Assim, para que as políticas públicas voltadas ao desenvolvimento possam ter impactos mais substantivos, torna-se fundamental adotar uma metodologia capaz de identificar as carências, necessidades, especificidades e potencialidades de cada macrorregião, para subdividi-las de acordo com determinados critérios sociais, econômicos, culturais e naturais visando à formulação e à implementação de políticas públicas intersetoriais. Constata-se ainda uma abordagem multidimensional e transversal do desenvolvimento, que se efetivará com ações públicas integradas nos três níveis federativos, apontando, assim, para uma política nacional de desenvolvimento, mas respeitando-se a integridade de cada um dos múltiplos territórios que constituem o país.

Outros aspectos que podem ser verificados no programa são a priorização de ações destinadas à descentralização da gestão territorial, a consolidação de uma estrutura de governança regional, bem como o estímulo à cooperação interinstitucional e ao fortalecimento de redes produtivas locais/regionais e de proteção social, com base numa pluralidade de atores de naturezas diversas (governos federal e estaduais, prefeituras, sociedade civil e setor empresarial), instituindo-se parcerias para o desenvolvimento. Estimula-se, assim, um desenvolvimento endógeno, sem, contudo, negar sua dimensão macroestrutural e a inserção do local/região "numa realidade mais ampla e complexa, com a qual interage e da qual recebe influências e pressões positivas e negativas" (BUARQUE, 1999). 
Outra iniciativa federal que claramente remete ao que foi aqui discutido é o programa Territórios da Cidadania, cuja finalidade é integrar as ações governamentais. O programa está estruturado em sete grandes eixos, nos quais são desenvolvidos diversos projetos e ações sociais destinados a diversas áreas territoriais.

Portanto, observa-se nessas proposições e em suas respectivas ações "uma combinação de relações geográficas verticais e horizontais", situadas "entre o endógeno e o exógeno" (SAQUET, 2007, p.112) nos processos de desenvolvimento territorial regional, apoiadas pela articulação de uma multiplicidade de atores. Nesse sentido, as políticas, programas e ações governamentais apresentados têm se pautado pela sobreposição de recortes (verticalidades e horizontalidades) e pela simultaneidade de forças, embora, na perspectiva de privilegiar e fortalecer as horizontalidades. Parecem tentar reconstruir, "a partir de ações localmente constituídas, uma base de vida que amplie a coesão da sociedade civil, a serviço do interesse coletivo" (SANTOS, 1997, p.227), apoiados em articulações homólogas, complementares e hierárquicas entre os atores envolvidos na promoção do desenvolvimento. Dessa forma, tais articulações podem revelar relações marcadas pelo poder e pela interação entre o local, o regional e o nacional.

Acrescente-se a essas proposições as inúmeras outras criadas nos âmbitos estadual, regional e municipal e têmse um volume considerável de iniciativas que, pelo montante de recursos que aportam e pelos impactos que podem acarretar, requerem suportes teóricos e metodológicos consistentes para acompanhamento, avaliação e reformulações, quando necessárias.

\section{Considerações finais}

O exercício teórico aqui desenvolvido teve a pretensão de destacar tanto o conceito de território como refletir sobre os acontecimentos que nele se produzem, principalmente, a partir de ações que, em tese, estão voltadas para o desenvolvimento das localidades.

Entendidos os acontecimentos como fruto de relações de poder, resgata-se, também, o caráter totalizante na abordagem do desenvolvimento, tanto quanto a necessidade de retorno aos projetos nacionais de desenvolvimento. Segundo Brandão (2007, p.199), "avançar nas análises territoriais [...] no Brasil passa, necessariamente, por pesquisas que buscam decifrar [...] formas especulativas, mercantis, patrimoniais, analisando suas estruturas locais de dominação". Os programas anteriormente referidos expressam consideração às especificidades do território. Nessa concepção, parecem privilegiar a endogenia dos territórios locais e regionais, inserindo-os numa realidade mais ampla, notadamente, a nacional, compreendendo que o desenvolvimento, além de ser um projeto-processo multidimensional, é de natureza transversal e que por isso mesmo envolve múltiplos interesses, conflitos e tensões.

As questões levantadas nesse artigo mostram, claramente, a necessidade de interação entre o território e suas localidades e as políticas públicas voltadas não só para o campo econômico como, particularmente, para o campo social e cultural. Na realidade, a gestão do território é um conjunto de ações estratégicas programadas para os espaços urbanos. Dessa perspectiva, as políticas públicas devem levar em conta a natureza do espaço, a especificidade de cada território e as condições histórico-estruturais de origem,

A conformação territorial é sempre uma articulação da população com as especificidades econômicas do lugar. Nesse sentido, alcançam dimensões simbólico-culturais que não podem ser negligenciadas. Quando ações articuladas às especificidades territoriais são, além de endógenas, fortalecidas por programas educativos e culturais, há sensível melhora no desempenho econômico, elevação do nível cultural e, consequentemente, qualificação da população. A inserção produtiva na economia global, desde que feita de forma qualitativa, tende a caracterizar uma melhoria no desempenho humano em cada limite territorial.

Na presente modernidade, o desenvolvimento local não se dissocia do desenvolvimento global. O local e o global são partes indissociáveis de estratégias e mudanças que se operam em escala global e que repercutem no cotidiano das comunidades. Estão aí os meios de comunicação a difundir a cultura global; são poderosos instrumentos de criação da cultura global em meio a territorialidades oriundas de estruturas históricas. 
Os programas de ordenamento territorial com fins sociais promovem, de um lado, a capacidade de planejamento e gestão estratégica e, de outro, a integração de ações de governo. Em ambos os casos, como nos planejamentos anteriores, o que se busca atingir - intencionalmente, pelo menos - é uma melhor qualidade de vida e distribuição de renda por meio de programas formativos.

As políticas públicas, portanto, voltar-se-ão para os territórios urbanos como centros promissores quanto à promoção de um maior nível cultural das populações em cenários de relações locais e globais. Os próximos decênios serão marcados pelas capacitações, as quais se colocam além de uma perspectiva estritamente local, ainda que estejam fundamentadas e sejam efetivamente produzidas no âmbito local. Por isso, as articulações Estado/sociedade devem não apenas considerar a realidade global, mas também possibilitar que esta seja apropriada pelas realidades locais. A cultura e a formação então geradas delinearão o perfil do indivíduo desta e da próxima modernidade. 


\section{Referências}

AMATO, J. N. Redes de cooperação produtiva e clusters regionais: oportunidades para as pequenas e médias empresas. São Paulo: Atlas, 2000.

BACELAR, T. Desenvolvimento regional: a descentralização valorizaria a diversidade. In: FLEURY, S. (Org.). Democracia, descentralização e desenvolvimento: Brasil \& Espanha. Rio de Janeiro: Editora FGV, 2006.

BALESTRIN, A.; VARGAS, L. Evidências teóricas para a compreensão das redes interorganizacionais. In: ENCONTRO NACIONAL DE ESTUDOS ORGANIZACIONAIS (ENEO), 2., 2002, Recife. Anais... Recife: [s.n.], 2002.

BARQUEIRO, A.V. Desenvolvimento endógeno em tempos de globalização. Porto Alegre: Fundação de Economia e Estatística, 2001.

BAUM, J. A. C.; INGRAM, P. Interorganizational learning and network organization: toward a behavioral theory of the interfirm. In: MARCH, J. G., AUGIER, M. (Ed.). A tribute to Richard M. Cyert. Aldershot (UK): Edward Elgar. 2000.

BRANDÃO, C. Território \& desenvolvimento: as múltiplas escalas entre o local e o global. Campinas: Ed. da Unicamp, 2007.

BRASIL. Constituição da República Federativa do Brasil. 9.ed. São Paulo: Saraiva, 1994.

Ministério da Integração Nacional. Política Nacional de Desenvolvimento Regional. Brasília, DF, [2004?]. Disponível em: <http://www.integracao.gov.br/programas>. Acesso em: 20 dez. 2007.

BUARQUE, S. C. Metodologia de planejamento e desenvolvimento local e municipal sustentável: material para orientação técnica e treinamento de multiplicadores e técnicos de planejamento local e municipal. Brasília, DF: Ministério Extraordinário de Política Fundiária, 1999.

CÂNDIDO, G. A. A Formação de redes interorganizacionais como mecanismo para geração de vantagem competitiva e para promoção do desenvolvimento regional: o papel do Estado e das políticas públicas neste cenário. READ - Revista Eletrônica da Administração (UFRGS), Porto Alegre, v.28, n.8, p.32-47, 2002.

CANO, W. Prefácio. In: BRANDÃO, C. Território \& desenvolvimento: as múltiplas escalas entre o local e o global. Campinas: Ed. da Unicamp, p.17-22, 2007.

CASTELLS, M. A sociedade em rede. São Paulo: Paz e Terra, 1999.

CONTI, S. Espaço global versus espaço local: perspectiva sistêmica do desenvolvimento local. In: DINIZ, C. C.; LEMOS, M. B. (Org.). Economia e território. Belo Horizonte: Editora UFMG, p.209-252, 2005.

DIAS, L. C. Redes: emergência e organização. In: CASTRO, I.; GOMES, P. C.; CORRÊA, Roberto L. (Org.). Geografia: conceitos e temas. 6.ed. Rio de Janeiro: Bertrand Brasil, v.1, p.141-162, 2003.

EDUARDO, M. F. Território, trabalho e poder: por uma geografia relacional. In: Campo-Território: revista de geografia agrária, v.1, n.2, p.173-195, ago. 2006.

FARAH, M. F. S. Parcerias, novos arranjos institucionais e políticas públicas no nível local de governo. Revista de Administração Pública, v.35, n.1, p.119-144, jan./fev. 2001.

FISCHER, T. Poderes locais, desenvolvimento e gestão: introdução a uma agenda. In: FICHER, T. (Org.). Gestão do desenvolvimento e poderes locais: marcos teóricos e avaliação. Salvador: Casa da Qualidade, 2002.

FURTADO, C. Introdução ao desenvolvimento: enfoque histórico-estrutural. 3.ed. rev. São Paulo: Paz e Terra, 2000.

GOULART, S. Uma abordagem ao desenvolvimento local inspirada em Celso Furtado e Milton Santos. Cadernos Ebape.BR, v.4, p.1-15, 2006. Disponível em: <www.ebape.fgv.br/cadesrnosebape>.

LOIOLA, E.; MOURA, S. Análise de redes: uma contribuição aos estudos organizacionais. In: FISCHER, T. (Org). Gestão contemporânea: cidades estratégicas e organizações locais. Rio de Janeiro: Fundação Getulio Vargas, 1996.

MISOCZKY, M. C. Redes e hierarquias: uma reflexão sobre os arranjos de gestão na busca de equidade em saúde. Revista de Administração Pública, v.37, n.2, p.335-354, 2001.

OLIVEIRA, F. Aproximações ao enigma: o que quer dizer desenvolvimento local? São Paulo: Pólis/Programa Gestão Pública e Cidadania/Eaesp/FGV, 2001. 
OLIVIERI, L. A importância histórico-social das redes. [2008?]. Disponível em: <http://www.cdh.org.br>. Acesso em: 3 dez. 2008.

PEREIRA, B., A., D. Estruturação de relacionamentos horizontais em redes. Porto Alegre, Tese (Doutorado) Departamento de Administração, EA/UFRGS, p. 219, 2005.

RADAMSKY, G.; SCHNEIDER, S. Nas teias da economia: o papel das redes sociais e da reciprocidade nos processos locais de desenvolvimento. Sociedade e Estado, v.22 n.2, maio/ago, 2007.

RAFFESTIN, C. Por uma geografia do poder. São Paulo: Atlas, 1993.

SANTOS, M. A natureza do espaço: técnica e tempo, razão e emoção. 2.ed. São Paulo: Hucitec, 1997.

. O retorno do território. In: SANTOS, M.; SOUZA, M. A.; SILVEIRA, M. L. (Org.). Território: globalização e fragmentação. 4.ed. São Paulo: Hucitec: Anpur, p.15-20, 1998.

. Modo de produção técnico-científico e diferenciação espacial. Revista Território, v.4, n.6, p.5-20, jan./jun. 1999.

. Por uma outra globalização: do pensamento único à consciência universal. 9.ed. Rio de Janeiro: Record, 2000.

. A natureza do espaço: técnica e tempo, razão e emoção. 4.ed. São Paulo: Edusp, 2006.

SAQUET, M. A. Abordagens e concepções sobre território. São Paulo: Expressão Popular, 2007.

VERSCHOORE, J. R. S. Redes de cooperação interorganizacional: a identificação de atributos e benefícios para um modelo de gestão. Tese (Doutorado) - PPGA/UFRGS, Porto Alegre, 2006.

VIEIRA, E. F., VIEIRA, M. M. F. Espaços econômicos: geoestratégia, poder e gestão do território. Porto Alegre: SagraLuzzatto, 2003.

A dialética da pós-modernidade: sociedade em transformação: Rio de Janeiro: FGV, 2004. 